\begin{tabular}{|c|c|c|}
\hline 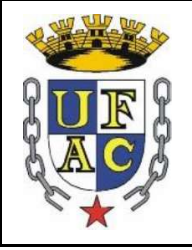 & $\begin{array}{c}\text { UÁQUIRI } \\
\text { Revista do Programa de Pós-Graduação em Geografia } \\
\text { UÁQUIRI - PPGGEO, v. 03, n. 01, p. 38-49, ano } 2021 \\
\text { Home page: https://periodicos.ufac.br/index.php/Uaquiri }\end{array}$ & PPG \\
\hline
\end{tabular}

\title{
ANÁLISE ACERCA DA TEORIA E MÉTODO UTILIZADO NO LIVRO A GEOGRAFIA DO ESPAÇO-MUNDO DE RUY MOREIRA.
}

\author{
Raquel Lins Brandão ${ }^{1 *}$, Juliana Santos de Souza Cunha ${ }^{1}$ \\ ORCID: https://orcid.org/0000-0001-9262-4600* e https://orcid.org/0000-0002-6980-3114
}

${ }^{1}$ Discentes da Universidade Federal do Acre, Programa de Pós-Graduação em Geografia, Rio Branco, Acre, Brasil.

*raquelbrandão40@gmail.com

Recebido em: 23/09/2020. Aceito em: 24/06/2021. Publicado em: 30/07/2021

DOI: https://doi.org/10.47418/uaquiri.vol3.n1.2021.4379

\begin{abstract}
RESUMO
Este artigo tem como principal objetivo discutir brevemente o tópico a sociedade do trabalho, contido no livro A Geografia do espaço-mundo - Conflitos e superações no espaço do capital, de Ruy Moreira, abordando e demonstrando em qual teoria ele se baseia para desenvolver a discussão, assim como o método utilizado por ele em sua obra. Para isso, foi necessário leituras e sistematizações não só da obra em si, mas também de leituras complementares sobre métodos e teorias, que serviram de aporte para explicitar porque a obra citada se encaixava em determinada teoria e/ou método. E a partir daí, analisar a importância de se conhecer cada teoria e cada método, através da compreensão de como eles influenciam a obra da qual fazem parte.
\end{abstract}

Palavras-chave: Teoria; Método; Sociedade; Trabalho; Capitalismo.

\section{ANAL YSIS ABOUT THE THEORY AND METHOD USED IN THE BOOK THE GEOGRAPHY OF RUY MOREIRA'S SPACE-WORLD.}

\begin{abstract}
This article has as main objective briefly discuss the topic of labor society being on the book "The Geography of space-world - Conflicts e overcomes at the capital space" by Rui Moreira, approaching and demonstrating in which theory it is based to depveloment the discussion as well as the method used in his piece. For that, it was necessary lectures and systematizations not only from the piece itself but also complemetary lectures about methods and theories that served to explain why the work cited fit a certain theory and/or method. From there, analise the importance of knowing each theory and each method, through the comprehension of how it influence the piece of which they are part of.
\end{abstract}

Keywords: Theory; Method; Society; Labor; Capitalism.

\section{ANÁLISIS ACERCA DE LA TEORÍA Y MÉTODO UTILIZADO EN EL LIBRO LA GEOGRAFÍA DEL ESPACIO-MUNDO DE RUY MOREIRA}

\section{RESUMEN}

Este artículo tiene como objetivo principal discutir brevemente sobre el tópico la sociedad del trabajo en el espacio del capital, de Ruy Moreira, abordando y demostrando en cuál teoría él se basa para 
desarrollar la discusión, así como el método utilizado por él en su obra. Para ello, fue necesario no solamente lecturas y sistematizaciones de la obra, sino también de lecturas complementarias sobre métodos y teorías, que sirvieron de aporte para explicitar el porqué la obra citada se encajaba en determinada teoría y/o método. A partir de ahí, analizar la importancia de que se conozca cada teoría y cada método, a través de la comprensión de cómo ellos influyen en la obra de la cual forman parte.

Palabras-clave: Teoría; Método; Sociedad; Trabajo; y Capitalismo.

\section{INTRODUÇÃO}

Este artigo visa discutir acerca da relevância da relação entre a teoria e o método a partir do livro A Geografia do espaço-mundo - Conflitos e superações no espaço do capital, de Ruy Moreira em consonância com abordagens no corpo teórico de outros autores.

Apresenta uma breve análise em relação ao que seria uma teoria e como ela se desenvolve, o que seria um método, alguns exemplos de métodos, suas principais diferenças e como eles influenciam no modo como a obra que os utiliza se estrutura. Esses métodos são escolhidos e utilizados a partir da teoria que serve de base para o estudo realizado.

Como forma de entender melhor essa questão, este artigo trabalha fazendo uma avaliação do livro A Geografia do espaço-mundo - Conflitos e superações no espaço do capital, de Ruy Moreira. Onde o autor descreve diversos elementos em cada capítulo para abordar os fundamentos, formas, contrastes, e transformações, da globalização, do capitalismo, da sociedade e do trabalho, além de muitos outros temas. O foco se deu na temática sobre a sociedade do trabalho, pois este assunto remente as concepções teóricas que já estudamos e desenvolvemos em outros trabalhos, e que desta forma continuarão a contribuir com a ampliação do conhecimento, além de certa propriedade e conforto já existente com o assunto abordado.

$\mathrm{O}$ artigo se estrutura, inicialmente de modo a apresentar brevemente o que seria uma teoria e o que seria um método, elencando alguns deles. Em seguida ocorre um breve resumo das principais ideias abordadas pelo autor no tópico em questão, como elas se desenvolvem, qual sua importância e por fim, são demostrados qual o método e teoria utilizados na obra estudada proporcionando melhor compreensão.

Objetivando-se desta forma, uma demonstração do quão importante é conhecer a teoria e o método utilizado por cada autor, pois isto influi diretamente em como o objeto de estudo será apresentado, estudado, abordado e desenvolvido, levando consequentemente a interpretações e resultados diferentes ao final de cada análise. 


\section{MATERIAL E MÉTODOS}

Inicialmente a discussão e temas abordados para a elaboração deste artigo ocorreram durante as aulas da disciplina de Teoria e Métodos, no Programa de Pós-Graduação em Geografia, da Universidade Federal do Acre. Em seguida, foram efetuadas diversas leituras e sistematizações dos textos disponibilizados na disciplina, e também em outros livros e artigos pesquisados por conta própria.

Depois de feita a leitura e as sistematizações, o artigo começou a ser escrito com o auxílio principal de duas obras, Geografia e Filosofia do Eliseu Savério Sposito, que possibilitou a discussão principal sobre os métodos, e $A$ Geografia do espaço-mundo, que além de sua rica contribuição teórica serviu de base para a demonstração de identificação da teoria e aplicabilidade do método.

Portanto, esse artigo foi construído com base em referenciais teóricos e bibliográficos, possibilitando e fundamentando a base de entendimento do assunto trabalhado.

\section{RESULTADOS E DISCUSSÃO}

A Geografia é de extrema importância para se discutir o espaço geográfico em sua dinâmica, a partir de ações e interações humanas que ao longo do tempo vem modificando, produzindo e reproduzindo esse espaço.

Estes acontecimentos estão relacionados com a necessidade de conhecer o local onde vivemos. Assim, o espaço geográfico pode ser entendido como o espaço produzido pelo homem e que está em constante transformação direta ou indiretamente através da ação humana ao longo do tempo, possuindo assim um caráter histórico.

Tendo como objetivo principal entender a dinâmica do espaço para auxiliar no planejamento das ações do homem sobre ele, a geografia busca entender as formas de relevo, os fenômenos climáticos, as composições sociais, os hábitos humanos em diferentes lugares do globo, reconhecendo sua importância para a manutenção da vida em sociedade.

Já a Ciência Geográfica, contém o conhecimento geográfico em partes, pois nem todo conhecimento geográfico é necessariamente ciência, afinal o censo comum pode ser um saber geográfico. O que vai caracterizar a construção do pensamento enquanto ciência são os paradigmas adotados, assim como a teoria e os métodos, explicados rapidamente a seguir.

Paradigma, conforme explicitado por Silva (2014), é uma palavra de origem grega que significa modelo, padrão de forma para ver, pensar e agir segundo uma determinada conduta situacional. Na história da Geografia e na sua interpretação e visão de mundo, dois paradigmas 
se destacaram "Nascia se assim a ciência como base numa visão paradigmática dualista: o determinismo versus o possibilismo." (SILVA, 2014, p.44,45).

Sposito por sua vez, elenca que os geógrafos têm se apoiado em vários paradigmas em suas investigações e buscas teóricas e empíricas, e define paradigma como "conjunto de ideias, teorias e doutrinas construídos com a intermediação do método e que caracterizam uma tendência científica." (2001, p.100).

Contudo, como especificado por Silva (2014, p. 47):

Tem-se uma dicotomia de paradigmas postos em condições opositoras: aquelas que reforçam as bases hegemônicas com instrumento técnico/científico; e, outra que busca ser instrumento de luta para transformar, revolucionar a realidade e contribuir com o processo de construção de um caminho para uma práxis científica libertadora.

Deste modo, esse padrão de ideias tanto poderia servir para compactuar e engrandecer teorias e questões já postas, como poderia servir de instrumento para combater ideias e práticas sociais colocadas historicamente que podem ser refutadas e discutidas, apresentando-se uma nova perspectiva como a Geografia em muitos momentos fez com o capitalismo.

Desta forma é importante salientar de acordo com Silva (2014, p. 47) que:

O resgate das contribuições dos geógrafos anarquistas e a aproximação ao marxismo foi condição fundamental para a construção de uma Geografia que não estivesse a serviço do capital, mas fosse instrumento para desvendar a realidade desigual e injusta por ele produzida; inclusive, sendo capaz de constituir num instrumento para transformá-la.

É importante ressaltar, como discutido por Sposito (2001), que quando se fala em paradigmas é fundamental abordar teoria, auxiliando na compreensão de como as ideias serão apresentadas e discutidas acerca da realidade, pois sem teoria e paradigma a ciência não se desenvolve.

Assim, teoria seria o conjunto de leis, conceitos e definições que ajudam a entender uma questão da sociedade. Essas teorias podem ter três caminhos distintos: primeiro, ela pode se estabelecer como fundamental e servir de base para o conhecimento durante muitos anos; segundo ela pode ser ultrapassada por outras teorias ou paradigmas e; terceiro, ela pode ser menosprezada e esquecida, como apresentado por Sposito (2001).

E por fim, o método, que seria de maneira simplória o caminho tomado para se chegar a algum lugar, uma série de metodologias lógicas e funcionais que possuem o intuito de auxiliar 
na compreensão de uma teoria posta. Assim o método funcionaria segundo Sposito (2004, p. 23):

[...] como instrumento intelectual e racional que possibilite a apreensão da realidade objetiva pelo investigador, quando este pretende fazer uma leitura dessa realidade e estabelecer verdades científicas para a sua interpretação.

Essa compreensão do autor nos leva a entender que o método consiste num conjunto de regras que visam atingir um resultado, proporcionando ao pesquisador chegar ao conhecimento verdadeiro sobre determinado objeto de estudo ligado diretamente a teoria que o fundamenta.

Os métodos podem ser os mais diversos, aqui optamos por destacar três deles: o método hipotético-dedutivo, o fenomenológico-hermenêutico e o método dialético.

O método hipotético-dedutivo segundo (JAPIASSU, MARCONDES, apud SPOSITO, 2004, p. 29-30) é aquele:

[...] através do qual se constrói uma teoria que formula hipóteses a partir das quais os resultados obtidos podem ser deduzidos, e com base nas quais se podem fazer previsões que, por sua vez, podem ser confirmadas ou refutadas.

É importante destacar que mesmo levando em consideração a neutralidade científica, neste método o objeto prevalece sobre o sujeito, isto é, o objeto de estudo acaba interferindo na pesquisa e no modo como o pesquisador irá trabalhar aquele objeto a partir de seus conhecimentos, e ao final, os resultados obtidos serão descritos a partir de hipóteses e deduções, como demonstrado por Sposito (2004).

O método fenomenológico-hermenêutico pode ser descrito conforme Sposito (2004, p. 38-39):

[...] contém a redução fenomenológica e a intencionalidade, indo além do subjetivismo através da consciência. Na pesquisa científica, a figura do pesquisador faz-se presente na redução do fenômeno para a sua abordagem total.

Ao contrário do hipotético-dedutivo, aqui o sujeito representa a figura central, predominando sobre o objeto estudado, pois é a descrição feita pelo sujeito que definirá o objeto, sendo assim o objeto é somente um elemento de análise que se destaca a partir das contribuições intelectuais que o sujeito atribui a ele, conforme explicado por Sposito (2004). 
Por último, temos o método dialético "[...] aquele que 'procede pela refutação das opiniões do senso comum, levando-as à contradição, para chegar então à verdade, fruto da razão." (JAPIASSU, MARCONDES, apud SPOSITO, 2004, p. 39). Aqui, a relação que ocorre entre sujeito e objeto realiza-se de maneira controversa, onde nenhum dos dois ganha o caráter de superioridade em relação ao outro, ambos se concebem e se modificam mutuamente, e desta forma, os trabalhos que se baseiam nesse método acabam tendo uma criticidade muito mais elevada, mostrando as contradições presentes na realidade e objeto estudado, de acordo com Sposito (2004).

\subsection{A sociedade do trabalho por Ruy Moreira.}

Em seu livro A Geografia do espaço-mundo - Conflitos e superações no espaço do capital, Ruy Moreira se fundamenta em diversos pontos para discutir itens como globalização, sociedade, trabalho e capital. Levando em consideração que nossos estudos se encaminham no intuito de analisar questões de trabalho na sociedade atual, com uma análise de como o capitalismo faz parte deste processo, optamos por discutir o tópico A sociedade do trabalho, contido no livro.

Moreira (2016), começa a discussão enfatizando que a sociedade tem em sua base de gênese e consolidação o trabalho, pois é justamente este elemento o responsável por organizar a estrutura das sociedades, o seu modo de produção, que implicam diretamente nas relações entre sociedade e trabalho, e em todas as consequências disso, que como podemos ver historicamente, principalmente com o advento do capitalismo, trazem em sua grande maioria, resultados muito nefastos.

O trabalho, ainda segundo o autor, seria uma relação de transação entre a sociedade e a natureza, onde ocorrem mutuamente trocas, consolidando desta forma um processo de produção, entre a matéria-prima fornecida pela natureza, e a energia, esforço ou como dito pelo autor a matéria corpórea do homem. Esta troca gera diversos tipos de trabalho, como discutido pelo autor quando elenca que:

\footnotetext{
O trabalho, tal como o vemos nas sociedades, é a atividade prática de gerar produtos a partir da relação de transformação dos elementos naturais ou semitransformados do local com que lida, cujo modo específico de ser depende do caráter da relação de propriedade dos meios de produção que emprega produtivamente, assim podendo-se falar do trabalho comunitário, escravo, servil, assalariado, correspondente à forma histórica de sociedade em que se desenvolve. (MOREIRA, 2016, p. 54).
} 
Ainda ocorre uma diferenciação entre dois tipos de trabalho, o concreto e o abstrato, segundo o autor, concreto seria o encontrado em todos os tipos de sociedade, sendo a atividade por meio da qual um produto seria gerado, já o abstrato seria aquele onde a principal relação é o valor gerado, os produtos gerados a partir do valor de troca alcançado, este tipo só pode ser encontrado nas sociedades de modo de produção capitalistas, onde as relações de mercado são o foco.

Deste modo, podemos perceber que a sociedade do trabalho é " [...] a forma de relação societária que surge na decorrência do surgimento do trabalho abstrato". (MOREIRA, 2016, p. 55). O que acaba levando a uma análise das sociedades pré-capitalistas e as capitalistas em si, que irão se organizar de modos diferentes, como exibido a seguir (Quadro 1):

\begin{tabular}{|c|c|}
\hline \multicolumn{2}{|c|}{ Quadro 1} \\
\hline Sociedades Pré-Capitalistas & Sociedades Capitalistas \\
\hline $\begin{array}{l}\text { Estabelecida e sistematizada pela } \\
\text { centração no trabalho concreto. }\end{array}$ & $\begin{array}{l}\text { Estabelecida e sistematizada pela centração } \\
\text { no trabalho abstrato. }\end{array}$ \\
\hline $\begin{array}{l}\text { Produção de valores de uso } \\
\text { (autossubsistência). }\end{array}$ & Produção de valores de troca (mercadorias). \\
\hline $\begin{array}{l}\text { Baseadas no trabalho produtor de valor } \\
\text { de uso. }\end{array}$ & $\begin{array}{l}\text { Baseadas no trabalho produtor de valor de } \\
\text { troca. }\end{array}$ \\
\hline $\begin{array}{l}\text { No processo de produção vão do } \\
\text { trabalho concreto ao usufruto direto do } \\
\text { valor de uso da natureza. }\end{array}$ & $\begin{array}{l}\text { Focadas na economia de mercado, vão do } \\
\text { trabalho abstrato ao valor de uso natural } \\
\text { orientado no valor de troca. }\end{array}$ \\
\hline
\end{tabular}

Fonte: MOREIRA, Ruy. A geografia do espaço-mundo: conflitos e superações no espaço do capital. Rio de Janeiro: Consequência Editora, 2016.

Org.: Raquel Brandão.

Diante desse processo de transição, e após a consolidação do capitalismo, a sociedade foi afetada drasticamente, pois o capital fez o homem escravo do próprio trabalho. O trabalho parou de ser um mecanismo de gratificação por assim dizer, tornando os indivíduos dignos de seu trabalho, e com condições para sua sobrevivência, para se transformar em um mecanismo que degrada seus sujeitos.

Os elementos utilizados pelo capital colocam o trabalhador em situação de exploração, enganação, com retornos lucrativos baixíssimos, com altas taxas de esgotamento físico, e ainda taxas de desemprego crescente, e o mais grave de todos é o recurso da alienação, que faz com 
que uma grande parcela de trabalhadores, não perceba os malefícios citados anteriormente, onde a responsabilidade recai totalmente em suas costas, gerando assim uma sociedade alienada.

\begin{abstract}
Portanto, a ação do capital transformando os processos de trabalho e seus resultados em valores de troca, submete o trabalho, de elemento humanizador, em elemento de dominação. Em outras palavras, não é o trabalho o agente de dominação, mas as relações sob o capital que o tornam condição de prisão do homem, já que o trabalho também se constitui condição para a emancipação humana. Assim, sob o modo capitalista de produção, contraditoriamente, o trabalho é transformado em algo alheio ao processo de emancipação do homem, exterior a si mesmo. O trabalho estranhado, alienado, separa o ser humano da sua condição de sujeito na relação homem-natureza e homemhomem, o que se materializa historicamente no distanciamento engendrado pelo capital entre o homem e os meios de produção, consubstanciando-se na propriedade privada, bem como na relação de assalariamento pelo processo de dominação entre sujeitos. (ALVES, 2014, p.98).
\end{abstract}

Assim, como concluído pelo próprio autor "[...] a sociedade do trabalho mostra a forma conspícua de sociabilidade alienada”. (MOREIRA, 2016, p. 57). Onde é possível destacar uma crise, na sociedade em si, e no modo como as relações de trabalho estão ocorrendo "a sociedade do trabalho transformando-se na sociedade dos serviços". (MOREIRA, 2016, p. 59).

Essa crise, chamada de "estrutural e sistémica" por Mészáros (2011) deu seus primeiros sinais nos anos de 1970, pela queda da taxa de lucro, esgotamento do padrão de acumulação taylorista/fordista de produção, crescimento excessivo da esfera financeira, crise do Welfare State e o advento evidente das privatizações. Na tentativa de sair da crise, o capital começou a se reestruturar, com uma nova ideologia e política de controle, notadamente a adoção do neoliberalismo, diminuição de direitos trabalhistas, privatizações, novas formas de trabalho como o empreendedorismo, colaboradores, trabalho intermitente, ocasionando uma precarização total. (ANTUNES, 2009; MÉSZÁROS, 2011).

Assim sendo, para se falar de sociedade é necessário se falar de trabalho que segundo Santos (2018, p. 20) "falar de trabalho é falar de transformação. Transformação do ser humano, sua história e seu meio, sendo uma troca constante entre homem e natureza". Corroborando com essa ideia Marx (2010, p. 211), diz que o trabalho "[...] é um processo de que participam o homem e a natureza, processo em que o ser humano, com sua própria ação, impulsiona, regula e controla seu intercâmbio material com a natureza". E como factualmente essa relação foi sendo construída a partir de uma evolução onde o homem não se apropriava mais do trabalho, mas se tornava um mecanismo dele, concomitante ao momento em que o capitalismo se tornou a base do modo de produção global. E esta relação é construída no seio das discussões geográficas, que se preocuparam sempre com o homem enquanto sociedade e suas relações com 
a natureza, e que gradativamente foi entendendo a importância de se analisar, discutir, debater (entender), e criticar a sociedade do trabalho que se estabeleceu com o passar dos anos.

Marx (2010) diz que o trabalho é assim uma condição de existência do homem, condição independente de todas as formas de sociedade, uma eterna necessidade natural para mediar troca material entre homem e natureza e, portanto, a vida humana.

Para exemplificar melhor o entendimento a esse respeito Marx traz o conceito de trabalho em uma passagem afirmando que "antes de tudo, o trabalho é um processo entre homem e natureza, um processo em que o homem, por sua própria ação, media, regula e controla seu metabolismo com a natureza" (MARX, 2013, p. 326).

A linha teórica que Ruy Moreira utiliza nesta obra é centrada e fundamentada no marxismo, onde o trabalho ocupa um papel essencial para o entendimento da sociedade em seu processo de gênese e desenvolvimento. Alicerçada em discutir a dinâmica entre dois grupos principais, o primeiro formado por um pequeno número de indivíduos que detém os meios de produção e o segundo na figura daqueles utilizados apenas como ferramentas para cumprir determinadas tarefas que gerarão lucro em grande escala para os primeiros. É importante salientar que este segundo grupo é o majoritário. Esses dois grupos são denominados no marxismo como burguesia e proletariado, respectivamente.

Entendendo basicamente como são compostos esses dois grupos, e a disparidade de benesses presentes em cada um, para não se falar na injustiça descarada do capitalismo, é necessário falar sobre a luta de classes que se torna inevitável como meio para tentar diminuir essa desigualdade entre esses dois grupos. Pois o modo de produção capitalista acaba gerindo e ditando todo o modelo de vida em sociedade, afetando também parâmetros intelectuais e políticos.

Por fim, essa teoria busca alinhar as reflexões postas nos estudos, com a veracidade de interpretar e esclarecer as engrenagens utilizadas no capitalismo para enganar, alienar, subjugar e se apropriar da sociedade, expondo o qual escusos e tirânicos são os mecanismos utilizados para esse fim. Assim como, propor ideias e saídas que possam levantar o questionamento a essa realidade imposta, e discutir sobre possíveis soluções que poderão modificar o modo de vida até então dominante. Segundo Santos (2018, p. 22), "isso porque nos dias de hoje, as transformações no trabalho e no mundo do trabalho adquirem uma importância central nos debates econômicos, políticos, nas ciências sociais e na sociedade em geral, em razão da profundidade de tais mudanças". 
Desta forma, o trabalho permeia a vida do ser humano desde a história de seu nascimento, ele é considerado uma máquina que move os setores de funcionamento de uma sociedade, pois é a partir do trabalho que o homem evolui, cria e recria suas condições de existência frente à reestruturação produtiva do capital, seja na esfera individual ou na esfera coletiva. Essa reestruturação do capital acabou precarizando ainda mais o trabalho nos dias de hoje. Em relação ao método:

Para Marx, a dialética compreende necessariamente a noção de movimento na História. Esse movimento ocorre quando, na confrontação de tese e antítese, a síntese contém aspectos positivos da tensão anterior, e apresenta-se como estágio superior que, por sua vez, se coloca também como uma nova tese. (SPOSITO, 2004, p. 44)

Ruy Moreira se utiliza desse método, que como já mostrado no início deste artigo, encaminha-se no sentido de contrapor as crenças populares, exibindo suas incoerências, a fim de apresentar-se a realidade, tal qual ela ocorre cotidianamente. $\mathrm{O}$ que pode ser visto como objetivo claramente na obra citada.

Mediante isso, Sposito (2004, p. 44) afirma que foi:

A concepção marxista de história, que possibilitou a elaboração de conceitos (renda absoluta, mercadorias) e de teorias (mais-valia, por exemplo), permitiu a mais elaborada leitura do capitalismo como modo de produção historicamente produzido com todas as suas determinações.

Portanto, para o autor essa concepção não só possibilitou a consolidação dos conceitos já formulados a respeito da origem do capitalismo, mas, também o entendimento de que o mesmo já vinha sendo propagado há muito tempo na história da humanidade e impondo suas formas de dominação, que aos poucos ia ganhando espaço no mundo hoje globalizado.

\section{CONSIDERAÇÕES FINAIS}

Este artigo se preocupou de maneira clara e objetiva possível, demonstrar e explicar o que seria um paradigma, uma teoria e um método, qual a importância de cada um para a estruturação de um trabalho, como eles auxiliam na construção e desenvolvimento do pensamento, no modo como as ideias serão apresentadas e como o objeto de estudo será abordado, a partir da análise acerca da teoria e método utilizado no livro A Geografia do espaçomundo de Ruy Moreira.

Isso influi diretamente em como os trabalhos irão se apresentar no seu resultado final, em como os desfechos descobertos se pautarão de modo diferente a partir de cada teoria e a 
partir de cada método. Por isso a importância de conseguir identificar ambos, e a necessidade de nas leituras está também ser uma preocupação, pois assim ficará mais claro a abordagem contida, e as críticas feitas.

Diante do exposto abordado neste artigo, buscou-se possibilitar a compreensão dessa importância, além de uma análise sobre como o trabalho influência na sociedade e como o trabalho é influenciado pelo capitalismo, a partir de uma visão pautada em uma discussão da teoria marxista, que metodologicamente pretende desvendar conhecimentos e exibir para a população as verdades secretas que muitas vezes não são enxergadas.

\section{AGRADECIMENTOS}

Gostaríamos de agradecer a Universidade Federal do Acre, mais especificamente ao Programa de Pós-Graduação em Geografia, pelas discussões propostas nas disciplinas e aos professores maravilhosos que enriqueceram as discussões e indicaram bibliografias que ajudaram a compor este artigo, além de proporcionarem um enriquecimento teórico profundo.

\section{REFERÊNCIAS}

ALVES, José. As revoltas dos trabalhadores em Jirau (RO): Degradação do trabalho represada na produção de energia elétrica na Amazônia. 2014. 671 f. Tese (Doutorado em Geografia) - Faculdade de Ciências e Tecnologia, da Universidade Estadual Paulista, Presidente Prudente (SP).

ANTUNES, Ricardo. Os sentidos do trabalho: ensaio sobre a afirmação e negação do trabalho. São Paulo: Boitempo, 2009.

MARX, Karl. O capital: crítica da economia política. V.1, Tradução: Rubens Enderle, São Paulo, Boitempo Editorial, 2013.

MARX, Karl. O capital: critica da economia política - Tradução SANT`ANNA, Reginaldo. 27 ed. Rio de Janeiro: Civilização brasileira, 2010. P. 211-231.

MÉSZÁROS, István. A crise estrutural do capital. São Paulo: Boitempo, 2011.

MOREIRA, Ruy. A geografia do espaço-mundo: conflitos e superações no espaço do capital. Rio de Janeiro: Consequência Editora, 2016.

SANTOS, Luiz Eduardo de Freitas. Trabalho no turismo: faces da precarização de um proletariado contemporâneo e de serviços / Luiz Eduardo de Freitas Santos; orientadora Rita de Cássia Ariza da Cruz. - São Paulo, 2018. 189 f. Dissertação (Mestrado). - Faculdade de Filosofia, Letras e Ciências Humanas da Universidade de São Paulo. Departamento de Geografia. Área de concentração: Geografia Humana. 
SILVA, Silvio Simione da. Da geografia vivida à geografia estudada: para além das formalidades acadêmicas - contradições, conflitos e proposições. Revista GeoUECE Programa de Pós-Graduação em Geografia da UECE Fortaleza/CE, v. 3, no5, p. 27-53, jul./dez. 2014. Disponível em: http://seer.uece.br/geouece.

SPOSITO, Eliseu Savério. A propósito dos paradigmas de orientações teóricometodológicas na Geografia contemporânea. Terra Livre, São Paulo, no 16, p.99-112, $1^{\circ}$ semestre/2001. Disponível em: http://agb.org.br/publicacoes/index.php/terralivre/article/view/351.

SPOSITO, Eliseu Savério. Geografia e Filosofia: contribuição para o ensino do pensamento geográfico. São Paulo: Editora UNESP, 2004. 